\title{
Reduced cement volume does not affect screw stability in augmented pedicle screws
}

\author{
Lukas Weiser $^{1} \cdot$ Kay Sellenschloh ${ }^{2} \cdot$ Klaus Püschel $^{3} \cdot$ Michael M. Morlock $^{2} \cdot$ Lennart Viezens $^{1} \cdot$ Wolfgang Lehmann $^{1}$. \\ Gerd Huber ${ }^{2}$
}

Received: 1 November 2019 / Revised: 5 March 2020 / Accepted: 11 March 2020 / Published online: 23 March 2020

(c) The Author(s) 2020

\begin{abstract}
Purpose Cement augmentation of pedicle screws is able to improve screw anchorage in osteoporotic vertebrae but is associated with a high complication rate. The goal of this study was to evaluate the impact of different cement volumes on pedicle screw fatigue strength.

Methods Twenty-five human vertebral bodies (T12-L4) were collected from donors between 73 and 97 years of age. Bone density (BMD) was determined by quantitative computed tomography. Vertebral bodies were instrumented by conventional pedicle screws, and unilateral cement augmentation was performed. Thirteen vertebrae were augmented with a volume of $1 \mathrm{ml}$ and twelve with a volume of $3 \mathrm{ml}$ bone cement. A fatigue test was performed using a cranial-caudal sinusoidal, cyclic load $(0.5 \mathrm{~Hz})$ with increasing compression force $(100 \mathrm{~N}+0.1 \mathrm{~N} /$ cycles $)$.

Results The load to failure was $183.8 \mathrm{~N}$ for the non-augmented screws and was increased significantly to $268.1 \mathrm{~N}(p<0.001)$ by cement augmentation. Augmentation with $1 \mathrm{ml}$ bone cement increased the fatigue load by $41 \%$ while augmentation with $3 \mathrm{ml}$ increased the failure load by $51 \%$ compared to the non-augmented screws, but there was no significant difference in fatigue loads between the specimens with screws augmented with $1 \mathrm{ml}$ and screws augmented with $3 \mathrm{ml}$ of bone cement $(p=0.504)$.

Conclusion Cement augmentation significantly increases pedicle screw stability. The benefit of augmentation on screw anchorage was not significantly affected by reducing the applied volume of cement from $3 \mathrm{ml}$ to $1 \mathrm{ml}$. Considering the high risk of cement leakage during augmentation, we recommend the usage of a reduced volume of $1 \mathrm{ml}$ bone cement for each pedicle screw.
\end{abstract}

\section{Graphic Abstract}

These slides can be retrieved under Electronic Supplementary Material
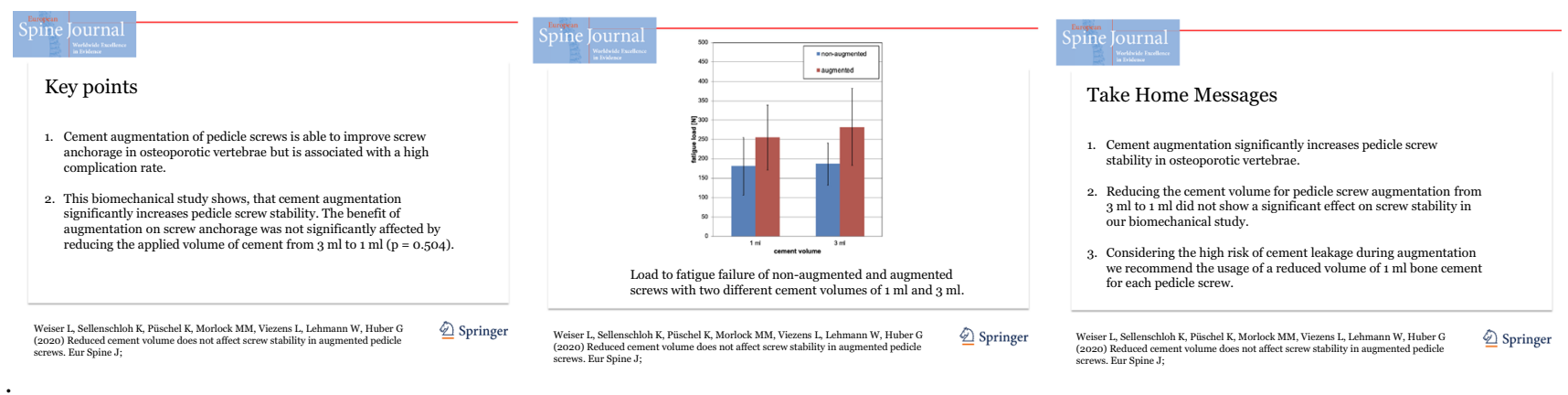

Keywords Pedicle screw $\cdot$ Cement augmentation $\cdot$ Cement volume $\cdot$ CAPSI $\cdot$ Bone mineral density

Electronic supplementary material The online version of this article (https://doi.org/10.1007/s00586-020-06376-w) contains supplementary material, which is available to authorized users.

Extended author information available on the last page of the article 


\section{Introduction}

Osteoporosis commonly causes vertebral fractures, and posterior spinal stabilization using pedicle screw fixation may be required [1-4]. However, various biomechanical studies have shown that pedicle screw fatigue load as well as pull-out force are significantly decreased in bone with reduced density and accordingly loosening of pedicle screws and progressive kyphotic deformity due to poor bone mineral density are frequently encountered in osteoporotic patients [5-11].

Cement augmentation of pedicle screws is increasingly used in order to improve fixation strength in osteoporotic patients [12-15]. Biomechanical studies have shown an approximately twofold increase in pull-out force and an increase in load to failure in cyclic testing by $52 \%$ for augmented pedicle screws [16-19]. However, cement augmentation of pedicle screws is associated with relevant complications such as leakage and embolism [20, 21]. Symptomatic complications are reported in 5.5\%, asymptomatic cement leakage in $66.7 \%$ and anaphylactic reactions in $1.2 \%$ of patients treated with augmented pedicle screws [21]. It has been shown that reducing the cement volume during augmentation is able to significantly reduce the risk of cement leakage [20]. Nevertheless, there is still controversy regarding the sufficient cement volume for screw augmentation.

The aim of this in vitro study was to evaluate the impact of different cement volumes on pedicle screw fatigue strength in osteoporotic/osteopenic vertebrae.

\section{Materials and methods}

Eight thoracolumbar spines (T12-L4) from human donors aged 73 years and above ( 3 female, 5 male) were collected. They were sealed in plastic bags and stored below $-20{ }^{\circ} \mathrm{C}$. While frozen, the specimens underwent computer tomography (CT) using a 16 row scanner (Brilliance 16 CT; Philips Healthcare, Hamburg, Germany). A solid calibration phantom (Bone Density Calibration Phantom; QRM, Moehrendorf, Germany) was included to determine the apparent volumetric bone mineral density (vBMD) of the vertebral bodies by linearly converting the Hounsfield unit (HU) from a defined voxel cube from the centre of the vertebral body to the phantom's reference densities (Avizo 5.1, VSG Inc., Burlington, MA). A total of 25 vertebral bodies with osteopenic/osteoporotic bone mineral density (BMD; below $100 \mathrm{mg} / \mathrm{cm}^{3}$ ) in which no bone changes such as fractures, osteolysis, implants or very unevenly distributed bone density, shown in the CT scan, were identified and included into the study (Table 1).
Table 1 Specimens given with age, gender, vertebral body level and corresponding BMD for the groups $1 \mathrm{ml}$ and $3 \mathrm{ml}$ cement augmentation

\begin{tabular}{|c|c|c|c|c|c|}
\hline Cement volume & Specimen & Age & Gender & Level & BMD \\
\hline $1 \mathrm{ml}$ & 1 & 86 & $\mathrm{f}$ & $\mathrm{L} 1$ & 50.0 \\
\hline $1 \mathrm{ml}$ & 2 & 78 & $\mathrm{~m}$ & $\mathrm{~L} 1$ & 79.7 \\
\hline $1 \mathrm{ml}$ & 5 & 83 & $\mathrm{~m}$ & L1 & 81.3 \\
\hline $1 \mathrm{ml}$ & 2 & 78 & $\mathrm{~m}$ & L2 & 89.2 \\
\hline $1 \mathrm{ml}$ & 4 & 97 & $\mathrm{~m}$ & L2 & 79.9 \\
\hline $1 \mathrm{ml}$ & 3 & 83 & $\mathrm{f}$ & L3 & 74.1 \\
\hline $1 \mathrm{ml}$ & 6 & 93 & $\mathrm{~m}$ & L3 & 47.4 \\
\hline $1 \mathrm{ml}$ & 7 & 83 & $\mathrm{f}$ & L3 & 76.1 \\
\hline $1 \mathrm{ml}$ & 8 & 73 & $\mathrm{~m}$ & L3 & 99.2 \\
\hline $1 \mathrm{ml}$ & 1 & 86 & $\mathrm{f}$ & L4 & 59.7 \\
\hline $1 \mathrm{ml}$ & 3 & 83 & $\mathrm{f}$ & L4 & 89.2 \\
\hline $1 \mathrm{ml}$ & 4 & 97 & $\mathrm{~m}$ & L4 & 70.3 \\
\hline $1 \mathrm{ml}$ & 7 & 83 & $\mathrm{f}$ & L4 & 80.7 \\
\hline Mean & & 84.8 & & & 75.1 \\
\hline SD & & 7.2 & & & 15.1 \\
\hline $3 \mathrm{ml}$ & 2 & 78 & $\mathrm{~m}$ & $\mathrm{~T} 12$ & 84.5 \\
\hline $3 \mathrm{ml}$ & 4 & 97 & $\mathrm{~m}$ & $\mathrm{~L} 1$ & 74.1 \\
\hline $3 \mathrm{ml}$ & 6 & 93 & $\mathrm{~m}$ & L1 & 43.3 \\
\hline $3 \mathrm{ml}$ & 1 & 86 & $\mathrm{f}$ & L2 & 56.1 \\
\hline $3 \mathrm{ml}$ & 3 & 83 & $\mathrm{f}$ & $\mathrm{L} 2$ & 87.9 \\
\hline $3 \mathrm{ml}$ & 5 & 83 & $\mathrm{~m}$ & L2 & 85.1 \\
\hline $3 \mathrm{ml}$ & 7 & 83 & $\mathrm{f}$ & L2 & 82.9 \\
\hline $3 \mathrm{ml}$ & 1 & 86 & $\mathrm{f}$ & L3 & 53.9 \\
\hline $3 \mathrm{ml}$ & 4 & 97 & $\mathrm{~m}$ & L3 & 83.8 \\
\hline $3 \mathrm{ml}$ & 2 & 78 & $\mathrm{~m}$ & L4 & 84.5 \\
\hline $3 \mathrm{ml}$ & 6 & 93 & $\mathrm{~m}$ & L4 & 52.7 \\
\hline $3 \mathrm{ml}$ & 8 & 73 & $\mathrm{~m}$ & L4 & 96.6 \\
\hline Mean & & 86.5 & & & 72.8 \\
\hline SD & & 7.8 & & & 17.4 \\
\hline
\end{tabular}

The specimens were thawed overnight and prepared for mechanical testing. Hence, dissection of the vertebrae and removal of the tissues care were taken to moisture the specimens with Ringer solution to prevent trying out of the tissue. Self-tapping, cannulated, augmentable, polyaxial screws $(6.0 \mathrm{~mm} \times 45 \mathrm{~mm}, \mathrm{CFX}$, DePuy Synthes Inc., West Chester, PA) were inserted under fluoroscopic guidance into both pedicles. Screws were positioned parallel to the vertebral end plate. After screw implantation, one screw was cement-augmented (VertaPlex HV, Stryker Inc., Kalamazoo, MI) - 12 vertebral bodies augmented with a volume of $3 \mathrm{ml}$ and 13 with $1 \mathrm{ml}$ of bone cement. Radiological assessment confirmed that the cement did not cross the midline (Fig. 1). The specimens were then embedded in the centre of a metal fixture with spherical shell. The inner concavity of the fixture enabled an embedding of the specimen in a way that the vertebral body may be surrounded by polyurethane resin 


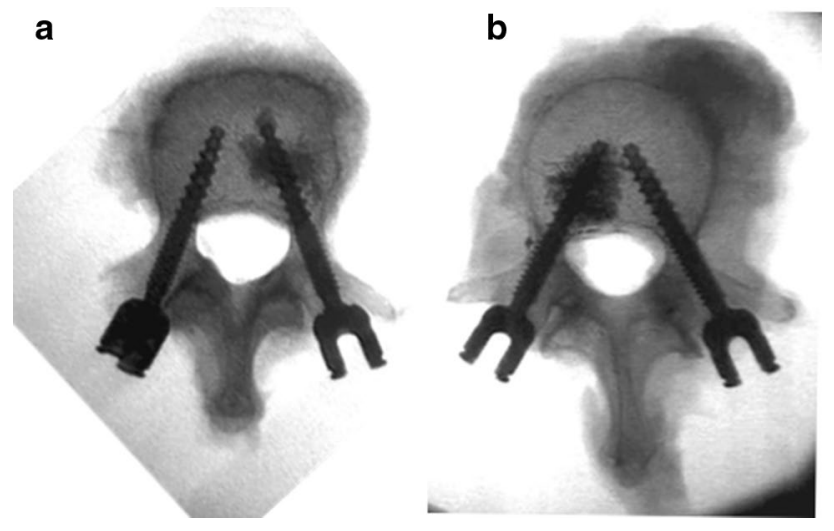

Fig. 1 Radiographs (transversal) showing vertebral body after instrumentation and cement augmentation of one side with $1 \mathrm{ml}$ (a) or $3 \mathrm{ml}$ (b)

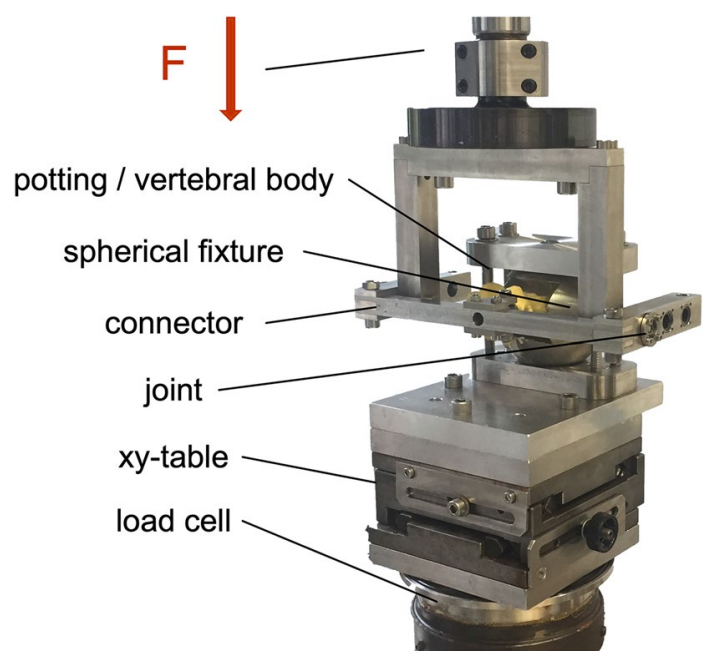

Fig. 2 Biomechanical test set-up. Specimens were embedded in a custom-made, spherical fixture which was fixed to a $\mathrm{x}-\mathrm{y}$ table. The fixture was aligned so that the pedicle screw was positioned exactly horizontal. The screw was linked to a frame by a rod and a blocker screw. A joint in the frame which was positioned exactly parallel to the screw head allowed movement with one degree of freedom. Load was applied from the cephalad direction

(RenCast FC 52/53, Huntsman Inc., Salt Lake City, UT), while the posterior arch and pedicle remained completely free (Fig. 2).

\section{Mechanical set-up}

The spherical fixture with the enclosed specimen was positioned on top of a $x-y$ table. The fixture enabled an exactly horizontal orientation of the pedicle screw, perpendicular to the actuator of the servo-hydraulic testing machine (MTS 858.2, MTS Systems, Eden Prairie, MN) and a perfect alignment of the loading direction between specimen and test machine. A frame structure connected the actuator and the pedicle screw using a short rod of $20 \mathrm{~mm}$ length (Expedium titanium 5.5 mm, DePuy Synthes Inc., West Chester, PA) and a blocker screw (Expedium Single Innie, DePuy Synthes Inc., West Chester, PA). A rotational joint in the connector was positioned orthogonal to the screw axis with its axis in the centre of the screw head-allowing movement with one degree of freedom (Fig. 2). The screw was not exhibited to reactive moments since the rotational axis of the test set-up was positioned in line with the sphere of the screw head. Thus, the head did not tilt with respect to the screw. Cyclic pulsating fatigue testing $(0.5 \mathrm{~Hz})$ was applied. Initially, load ranged from $50 \mathrm{~N}$ to $100 \mathrm{~N}$, which represents physiological walking [22]. To care for the trade-off between physiological loading and changed material properties due to degradation during testing, the time to provoke fatigue failure was accelerated by stepwise increasing the maximum compressive force by $0.1 \mathrm{~N}$ every cycle [23], e.g. after 1000 cycles the load ranged from $50 \mathrm{~N}$ to $200 \mathrm{~N}$. Cyclic loading was terminated after the displacement of the screw heads exceeded $5.4 \mathrm{~mm}$ (approximately $20^{\circ}$ rotation). Testing was consecutively performed for the non-augmented and augmented side, minimizing the risk of cross-effects due to a moving cement seal.

\section{Parameters}

The failure load at the end of the testing, the construct's stiffness at the beginning, at 50\%, 75\% and those at the end of testing were determined (MATLAB, The MathWorks Inc., Natick, MA). Loosening was evaluated based on post-test CT scans, but no scoring system or quantification has been done.

Statistical analysis with a type I error probability of $\alpha=0.05$ was performed (SPSS, version 21, IBM, Armonk, NY). Nonparametric Mann-Whitney U test and Kruskal-Wallis test were used to compare the stiffness of the different groups - especially with regard to the changes with time. A repeated measurement analysis with the innersubject factors non-augmented/augmented was performed to test the in-between subjects effect of the different volumes used for the augmentation. A linear regression analysis was performed to investigate the influence of BMD on the fatigue load. If not stated differently, summary data are given as mean value \pm standard deviation.

\section{Results}

Donors' age was above 73 years ( $85 \pm 7$ years) and BMD below $100 \mathrm{mg} / \mathrm{cm}^{3}\left(74.5 \pm 15.9 \mathrm{mg} / \mathrm{cm}^{3}\right)$ in each vertebral body. Consequently, each specimen may be considered to be osteopenic or osteoporotic [24]. Both groups (1 ml and $3 \mathrm{ml}$ ) included vertebrae from various spinal levels, but neither the 
age nor the bone density differed significantly between these groups (age $p=0.769$; BMD $p=0.810$ ) (Table 1).

Post-fatigue testing CT scans exhibited a caudal displacement of the screw head and a cranial displacement of the screw tip. The centre of rotation was located in the area of the pedicle. All screws showed signs of loosening but no tilting of the screw heads.

Initially the stiffness of the augmented and non-augmented screws did not differ $(p=0.487)$, but at the end of testing the augmented screws exhibited a significantly lower stiffness compared to the non-augmented screws ( $p=0.044$; $165 \pm 43 \mathrm{~N} / \mathrm{mm}$ vs. $190 \pm 39 \mathrm{~N} / \mathrm{mm}$ ). In the three groups (augmented $1 \mathrm{ml}$, augmented $3 \mathrm{ml}$ and non-augmented), the stiffness decreased significantly with ongoing loading (augmented $1 \mathrm{ml} p=0.008$; augmented $3 \mathrm{ml} p<0.001$; and non-augmented $p=0.002$ ) (Table 2).

The load to failure for the non-augmented side in the two groups $(1 \mathrm{ml} / 3 \mathrm{ml})$ hardly differed $(181 \mathrm{~N} \pm 74 \mathrm{~N}$ vs $187 \pm 54 \mathrm{~N})$, but the corresponding cement-augmented screws ( $1 \mathrm{ml}$ vs $3 \mathrm{ml}$ ) withstand a 40 to $50 \%$ higher load $(255 \pm 84 \mathrm{~N}$ and $282 \pm 100 \mathrm{~N})$. The repeated measure general linear model exhibited that this increase due to cement augmentation was significant ( $p<0.001$, power 0.999 ), but neither a significant interaction between cement augmentation and cement volume $(p=0.504$, power 0.100$)$ nor a difference between the two groups of specimens $(p=0.553$, power 0.089) could have been observed-although the power was low due to restricted sample size and the small $10 \%$ differences between augmentations with $1 \mathrm{ml}$ and $3 \mathrm{ml}$ (Table 3, Fig. 3).

There was a significant correlation between the BMD and fatigue load in the non-augmented as well as in the augmented screws (Fig. 4). The highest coefficient of determination was found for the non-augmented screws and the lowest for the screws augmented with $3 \mathrm{ml}$ cement (non-augmented: $r^{2}=0.602, p<0.001$; augmented $1 \mathrm{ml}: r^{2}=0.462$, $p=0.011$; augmented $3 \mathrm{ml}: r^{2}=0.379, p=0.033$ ).

\section{Discussion}

Due to demographic changes with a growing elderly population, spine surgeons face more and more osteoporotic patients. Since BMD is crucial for pedicle screw stability,
Table 2 Stiffness of augmented $(1 \mathrm{ml} / 3 \mathrm{ml})$ and non-augmented screws at the beginning, at $50 \%$, $75 \%$ and at the end of testing (mean and SD)

\begin{tabular}{|c|c|c|c|c|c|c|c|c|c|}
\hline \multirow[t]{2}{*}{ Stiffness } & \multicolumn{2}{|c|}{$\begin{array}{l}\text { Start (N/ } \\
\mathrm{mm})\end{array}$} & \multicolumn{2}{|c|}{$50 \%(\mathrm{~N} / \mathrm{mm})$} & \multicolumn{2}{|c|}{$75 \%(\mathrm{~N} / \mathrm{mm})$} & \multicolumn{2}{|c|}{ End $(\mathrm{N} / \mathrm{mm})$} & \multirow[t]{2}{*}{$p$ value start vs. end } \\
\hline & Mean & SD & Mean & $\mathrm{SD}$ & Mean & $\mathrm{SD}$ & Mean & SD & \\
\hline Augmented $1 \mathrm{ml}$ & 247.0 & 75.9 & 235.1 & 63.3 & 216.3 & 53 & 177.1 & 51.1 & 0.008 \\
\hline Augmented $3 \mathrm{ml}$ & 237.3 & 71.9 & 217.8 & 52.7 & 198.5 & 42.4 & 152.8 & 29.4 & $<0.001$ \\
\hline Augmented $1 \mathrm{ml}+3 \mathrm{ml}$ & 242.4 & 72.6 & 226.8 & 57.8 & 207.83 & 48 & 165.4 & 43.1 & $<0.001$ \\
\hline Non-augmented & 242.4 & 61.6 & 235.4 & 52.6 & 217.4 & 41 & 189.6 & 39.4 & 0.002 \\
\hline$p$ value & \multicolumn{2}{|c|}{0.487} & \multicolumn{2}{|c|}{0.318} & \multicolumn{2}{|c|}{0.387} & \multicolumn{2}{|c|}{0.044} & \\
\hline
\end{tabular}

Bold indicates significant $p$ values $(<0.05)$

The $p$ values were given for the comparison between the stiffness at the start and the end of testing and for the comparison between augmented and non-augmented screws

Table 3 Results of repeated measurement analyses with analysis of inter-subject effects treatment (augmentation) and fatigue load for augmented and non-augmented screws (mean and SD)

\begin{tabular}{|c|c|c|c|}
\hline Group (ml) & Mean $(\mathrm{N})$ & $\mathrm{SD}(\mathrm{N})$ & $N$ \\
\hline \multicolumn{4}{|l|}{ Non-augmented } \\
\hline 1 & 180.8 & 74.0 & 13 \\
\hline 3 & 187.1 & 54.1 & 12 \\
\hline Total & 183.8 & 63.9 & 25 \\
\hline \multicolumn{4}{|l|}{ Augmented } \\
\hline 1 & 255.0 & 84.3 & 13 \\
\hline 3 & 282.3 & 99.6 & 12 \\
\hline Total & 268.1 & 91.1 & 25 \\
\hline Analyses of intra-subject effects & \multicolumn{2}{|r|}{ Significance } & Power \\
\hline Non-augmented vs. augmented side & \multicolumn{2}{|r|}{$<0.001$} & 0.999 \\
\hline Treatment ( $1 \mathrm{ml}$ vs. $3 \mathrm{ml})$ & \multicolumn{2}{|r|}{0.504} & 0.1 \\
\hline
\end{tabular}

$P$ values for the comparison of augmented and non-augmented screws 


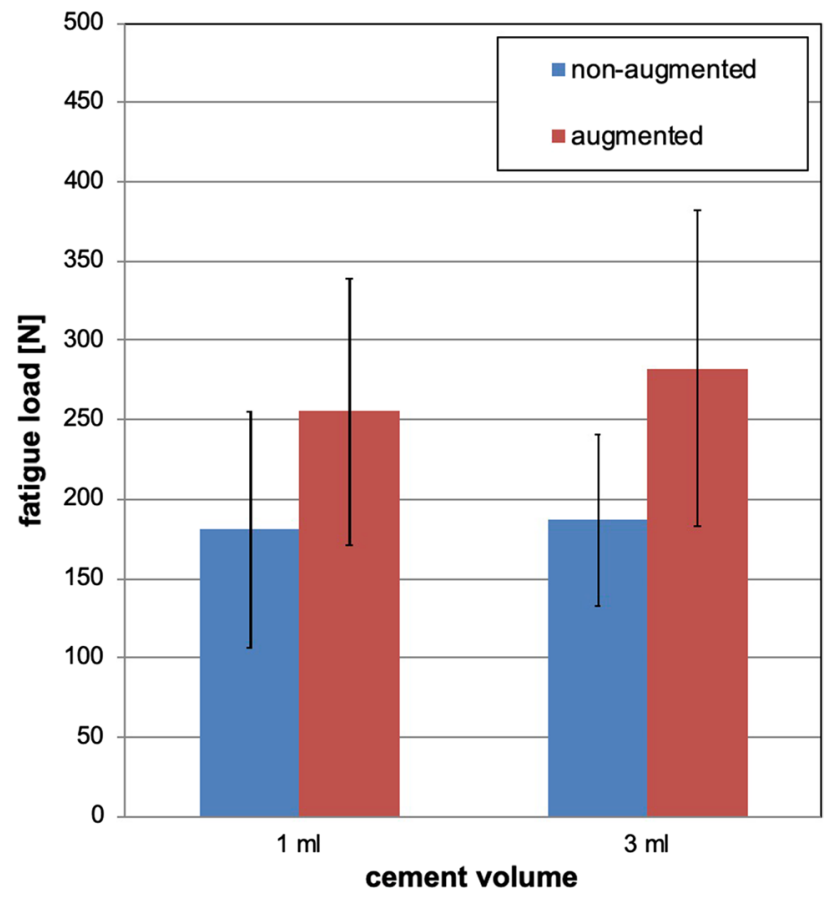

Fig. 3 Load to fatigue failure of non-augmented and augmented screws with two different cement volumes of $1 \mathrm{ml}$ and $3 \mathrm{ml}$

screw loosening is a relevant complication, especially in these patients $[6,11,16]$. There are different techniques to improve screw anchorage, e.g. expandable screws, lengthening of the construct or cement augmentation of the pedicle screws [25-27]. Clinical and biomechanical studies exhibited the benefits of augmentation in terms of higher pull-out forces, increasing fatigue loads in cyclic testing and reduced loosening rates in clinical studies [12, $14,23,25]$. Hence, this has received growing attention.
With increasing usage, concerns regarding the potential complication associated with these procedures rise.

Janssen et al. showed the extremely high rate of $66.7 \%$ asymptomatic cement leakage in patients with augmented pedicle screws [21] and a rate of pulmonary cement embolism in $7.9 \%$ of patients of whom $3 \%$ were symptomatic. Overall, they described symptomatic complications in 5.5\% of cases and a 30-day mortality rate of $1.8 \%$ [21]. Guo et al. performed a retrospective analysis of 202 patients with 950 augmented pedicle screws and observed a cement leakage in $81.7 \%$ of patients [20]. They further investigated the factors influencing the occurrence of cement leakage and found a significant relation to the cement volume with an odds ratio of 0.75 ( $p=0.013$ ). Additionally, the high rate of observed cement leakage in kyphoplasty illustrates the potential danger of using cement on the spine [28].

There is only minor evidence regarding the optimal cement volume for pedicle screw augmentation yet. Pishnamaz et al. performed a biomechanical study regarding screw stability after augmentation with a cement volume of $4 \mathrm{ml}$ and $1.5 \mathrm{ml}$ [29]. They showed no significant benefit of an increased cement volume in pull-out testing and conclude that the pedicle screw stability of high-volume augmented screws is disadvantageous compared to moderately augmented screws. However, they were not able to draw this conclusion based on a cyclic fatigue test, which is a more physiological testing method for screw failure testing [23, 30]. especially since withdrawing of the screws posteriorly through the pedicle has clinically rarely been reported $[12$, 23, 27, 31].

The used test design with a repeated, stepwise increasing force within the physiological range [22] exhibited a continuously decreasing stiffness which most probably indicates slight damages of the trabecular bone [32]. This results in an in vivo-like failure pattern expressed in a cranio-caudal
Fig. 4 Correlation between the achieved fatigue load and vertebrae's BMD for the non-augmented (black), $1 \mathrm{ml}$ augmented (green) and $3 \mathrm{ml}$ augmented (red) screws

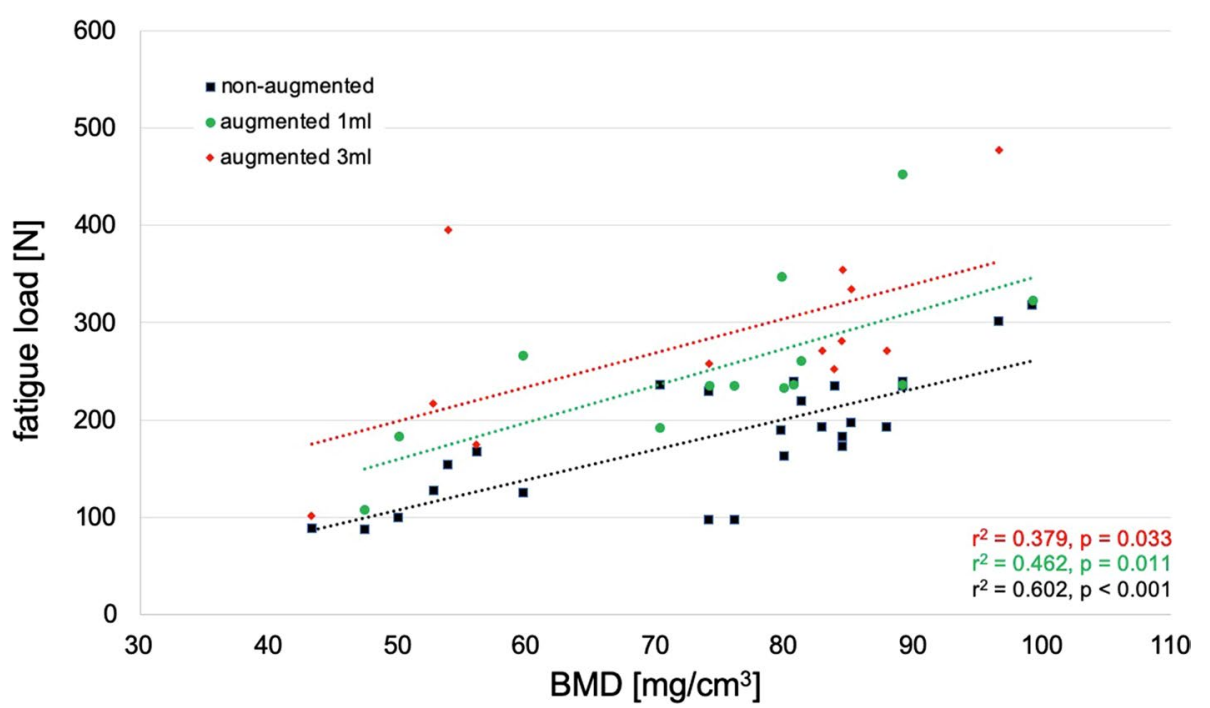


loosening of the pedicle screws. A significantly lesser stiffness of the augmented screws compared to the non-augmented screws at the end of testing was observed. However, it has to be kept in mind that the augmented screws bore a reasonable higher load at the end of the testing. It is suggested that the pivot point of screw toggling moved further into the vertebral body with augmentation. This would result in an increased lever arm and consequently the loss of fatigue stiffness.

Alike to other biomechanical studies, a significant better screw anchorage in augmented screws compared with non-augmented screws was found. Regarding the cement volume, an increase of $41 \%$ of fatigue load using only $1 \mathrm{ml}$ bone cement was observed. A lager amount of bone cement of $3 \mathrm{ml}$ showed a fatigue load which was increased by $51 \%$ compared to non-augmented which differed nonsignificantly from the augmentation with $1 \mathrm{ml}$. Although the load to failure of $282 \mathrm{~N}$ for $3 \mathrm{ml}$ cement was a bit higher compared to $255 \mathrm{~N}$ for $1 \mathrm{ml}$, we could not find a statistical significance. However, for such a small difference in mean a higher power could only be received with an ethically unjustifiable number of specimens.

Keeping the high complication rate of pedicle screw augmentation in mind and considering that a reduced cement volume is able to reduce the risk of cement leakage significantly, these results have a high impact.

As exhibited by others using a similar testing set-up [11, 19], there was a significant correlation between the BMD and the failure load. It has been shown that cement augmentation should only be used if the bone density of the corresponding vertebral body is reduced [19]. For this reason, only vertebral bodies with significantly reduced BMD were included into this study. Despite this small range of bone density, we were able to show a significant correlation, even if the coefficient of determination is lower compared to the studies focusing on the influence of bone density.

Common limitations of in vitro studies have to be regarded, especially restricted sample size and normal variations due to the use of human vertebrae from varying spinal levels. Vertebral bodies from the levels T12-L4 are mostly affected from osteoporotic fractures, but differ in volume and anatomy. Nevertheless, the cement volume and the screw diameter were not adapted to the specimens. This was done to prevent artificial bias of the study and is in accordance with clinical routines anyway. Inconsistencies with regard to the screw insertion, e.g. the angle, direction and entry point of the pedicle screws, may also have a minor influence on the results, but not differently to the situation in vivo. Factors associated with the testing set-up such as subsidence of the specimen fixation or deformation of the setting could also influence the results. To reduce specimen degradation, a set-up with continuous increasing load was used. Therefore, the measured failure loads are on the upper range or above the loads that probably occur in patients during physiological activities [22].

\section{Conclusion}

Despite that a biomechanical cadaver model is not able to perfectly simulate in vivo conditions, it could be concluded that cement augmentation significantly increases pedicle screw stability, but no significant differences between the applied cement volumes of $1 \mathrm{ml}$ and $3 \mathrm{ml}$ could be seen. Considering the high risk of cement leakage during augmentation, a spare usage of bone cement (around $1 \mathrm{ml}$ ) for each pedicle screw appears to be recommendable-at least if a mechanical integer construct can be realized.

Acknowledgements Open Access funding provided by Projekt DEAL.

\section{Compliance with ethical standards}

Conflict of interest The authors declare that they have no conflict of interest.

Open Access This article is licensed under a Creative Commons Attribution 4.0 International License, which permits use, sharing, adaptation, distribution and reproduction in any medium or format, as long as you give appropriate credit to the original author(s) and the source, provide a link to the Creative Commons licence, and indicate if changes were made. The images or other third party material in this article are included in the article's Creative Commons licence, unless indicated otherwise in a credit line to the material. If material is not included in the article's Creative Commons licence and your intended use is not permitted by statutory regulation or exceeds the permitted use, you will need to obtain permission directly from the copyright holder. To view a copy of this licence, visit http://creativecommons.org/licenses/by/4.0/.

\section{References}

1. Burge R, Dawson-Hughes B, Solomon DH, Wong JB, King A, Tosteson A (2007) Incidence and economic burden of osteoporosis-related fractures in the United States, 2005-2025. J Bone Miner Res 22(3):465-475

2. Cho W, Cho SK, Wu C (2010) The biomechanics of pedicle screwbased instrumentation. J Bone Joint Surg Br 92(8):1061-1065

3. Gaines RW Jr (2000) The use of pedicle-screw internal fixation for the operative treatment of spinal disorders. J Bone Joint Surg Am 82-A(10):1458-1476

4. Wood KB, Li W, Lebl DR, Ploumis A (2014) Management of thoracolumbar spine fractures. Spine J 14(1):145-164

5. Coe JD, Warden KE, Herzig MA, McAfee PC (1990) Influence of bone mineral density on the fixation of thoracolumbar implants. A comparative study of transpedicular screws, laminar hooks, and spinous process wires. Spine (Phila Pa 1976) 15(9):902-907

6. Galbusera F, Volkheimer D, Reitmaier S, Berger-Roscher N, Kienle A, Wilke HJ (2015) Pedicle screw loosening: a clinically relevant complication? Eur Spine J 24(5):1005-1016

7. Halvorson TL, Kelley LA, Thomas KA, Whitecloud TS 3rd, Cook SD (1994) Effects of bone mineral density on pedicle screw fixation. Spine (Phila Pa 1976) 19(21):2415-2420

8. Paxinos O, Tsitsopoulos PP, Zindrick MR, Voronov LI, Lorenz MA, Havey RM, Patwardhan AG (2010) Evaluation of pullout strength and failure mechanism of posterior instrumentation in normal and osteopenic thoracic vertebrae. J Neurosurg Spine 13(4):469-476 
9. Wittenberg RH, Shea M, Swartz DE, Lee KS, White AA 3rd, Hayes WC (1991) Importance of bone mineral density in instrumented spine fusions. SpineSpine (Phila Pa 1976) 16(6):647-652

10. Wu ZX, Gong FT, Liu L, Ma ZS, Zhang Y, Zhao X, Yang M, Lei W, Sang HX (2012) A comparative study on screw loosening in osteoporotic lumbar spine fusion between expandable and conventional pedicle screws. Arch Orthop Trauma Surg 132(4):471-476

11. Weiser L, Huber G, Sellenschloh K, Viezens L, Puschel K, Morlock MM, Lehmann W (2017) Insufficient stability of pedicle screws in osteoporotic vertebrae: biomechanical correlation of bone mineral density and pedicle screw fixation strength. Eur Spine J 26(11):2891-2897

12. Bostelmann R, Keiler A, Steiger HJ, Scholz A, Cornelius JF, Schmoelz W (2017) Effect of augmentation techniques on the failure of pedicle screws under cranio-caudal cyclic loading. Eur Spine J 26(1):181-188

13. Chang MC, Kao HC, Ying SH, Liu CL (2013) Polymethylmethacrylate augmentation of cannulated pedicle screws for fixation in osteoporotic spines and comparison of its clinical results and biomechanical characteristics with the needle injection method. J Spinal Disord Technol 26(6):305-315

14. Hoppe S, Keel MJ (2017) Pedicle screw augmentation in osteoporotic spine: indications, limitations and technical aspects. Eur J Trauma Emerg Surg 43(1):3-8

15. Sawakami K, Yamazaki A, Ishikawa S, Ito T, Watanabe K, Endo N (2012) Polymethylmethacrylate augmentation of pedicle screws increases the initial fixation in osteoporotic spine patients. J Spinal Disord Technol 25(2):E28-E35

16. Choma TJ, Pfeiffer FM, Swope RW, Hirner JP (2012) Pedicle screw design and cement augmentation in osteoporotic vertebrae: effects of fenestrations and cement viscosity on fixation and extraction. Spine (Phila Pa 1976) 37(26):E1628-E1632

17. Leichtle CI, Lorenz A, Rothstock S, Happel J, Walter F, Shiozawa T, Leichtle UG (2016) Pull-out strength of cemented solid versus fenestrated pedicle screws in osteoporotic vertebrae. Bone Joint Res 5(9):419-426

18. Liu D, Wu ZX, Pan XM, Fu SC, Gao MX, Shi L, Lei W (2011) Biomechanical comparison of different techniques in primary spinal surgery in osteoporotic cadaveric lumbar vertebrae: expansive pedicle screw versus polymethylmethacrylate-augmented pedicle screw. Arch Orthop Trauma Surg 131(9):1227-1232

19. Weiser L, Huber G, Sellenschloh K, Viezens L, Puschel K, Morlock MM, Lehmann W (2018) Time to augment?! Impact of cement augmentation on pedicle screw fixation strength depending on bone mineral density. Eur Spine J 27(8):1964-1971

20. Guo HZ, Tang YC, Guo DQ, Zhang SC, Li YX, Mo GY, Luo PJ, Zhou TP, Ma YH, Liang Jiang XB (2019) The cement leakage in cement-augmented pedicle screw instrumentation in degenerative lumbosacral diseases: a retrospective analysis of 202 cases and 950 augmented pedicle screws. Eur Spine J 28(7):1661-1669

21. Janssen I, Ryang YM, Gempt J, Bette S, Gerhardt J, Kirschke JS, Meyer B (2017) Risk of cement leakage and pulmonary embolism by bone cement-augmented pedicle screw fixation of the thoracolumbar spine. Spine J 17(6):837-844

22. Rohlmann A, Bergmann G, Graichen F (1997) Loads on an internal spinal fixation device during walking. J Biomech 30(1):41-47

23. Kueny RA, Kolb JP, Lehmann W, Puschel K, Morlock MM, Huber $G$ (2014) Influence of the screw augmentation technique and a diameter increase on pedicle screw fixation in the osteoporotic spine: pullout versus fatigue testing. Eur Spine J 23(10):2196-2202

24. American College of Radiology (2014) ACR-SPR-SSR Practice Parameter for the Performance of Quantitative Computed Tomography (QCT) Bone Densitometry. https://www.acr.org/ /media/ ACR/Documents/PGTS/guidelines/QCT.pdf

25. Cao Y, Liang Y, Wan S, Jiang C, Jiang X, Chen Z (2018) Pedicle screw with cement augmentation in unilateral transforaminal lumbar interbody fusion: a 2-year follow-up study. World Neurosurg 118:e288-e295

26. Gazzeri R, Roperto R, Fiore C (2016) Surgical treatment of degenerative and traumatic spinal diseases with expandable screws in patients with osteoporosis: 2-year follow-up clinical study. J Neurosurg Spine 25(5):610-619

27. Weiser L, Dreimann M, Huber G, Sellenschloh K, Puschel K, Morlock MM, Rueger JM, Lehmann W (2016) Cement augmentation versus extended dorsal instrumentation in the treatment of osteoporotic vertebral fractures: a biomechanical comparison. Bone Joint J 98 B(8):1099-1105

28. Riesner HJ, Kiupel K, Lang P, Stuby F, Friemert B, Palm HG (2016) Clinical relevance of cement leakage after radiofrequency kyphoplasty vs balloon kyphoplasty: a prospective randomised study. Z Orthop Unfall 154(4):370-376

29. Pishnamaz M, Lange H, Herren C, Na HS, Lichte P, Hildebrand F, Pape HC, Kobbe P (2018) The quantity of bone cement influences the anchorage of augmented pedicle screws in the osteoporotic spine: a biomechanical human cadaveric study. Clin Biomech (Bristol, Avon) 52:14-19

30. Mengis C, Schmoelz W, Duart Clemente JM, Alvarez-Galovich L (2018) Letter to the editor regarding "The quantity of bone cement influences the anchorage of augmented pedicle screws in the osteoporotic spine: A biomechanical human cadaveric study" by Pishnamaz M et al. Clin Biomech 52:14-19. Clin Biomech (Bristol, Avon) 59:211

31. Schulze M, Gehweiler D, Riesenbeck O, Wahnert D, Raschke MJ, Hartensuer R, Vordemvenne T (2016) Biomechanical characteristics of pedicle screws in osteoporotic vertebrae-comparing a new cadaver corpectomy model and pure pull-out testing. J Orthop Res 35(1):167-174

32. Kiner DW, Wybo CD, Sterba W, Yeni YN, Bartol SW, Vaidya $\mathrm{R}$ (2008) Biomechanical analysis of different techniques in revision spinal instrumentation: larger diameter screws versus cement augmentation. Spine (Phila Pa 1976) 33(24):2618-2622

Publisher's Note Springer Nature remains neutral with regard to jurisdictional claims in published maps and institutional affiliations.

\section{Affiliations}

\section{Lukas Weiser $^{1} \cdot$ Kay Sellenschloh ${ }^{2} \cdot$ Klaus Püschel $^{3} \cdot$ Michael M. Morlock $^{2} \cdot$ Lennart Viezens $^{1} \cdot$ Wolfgang Lehmann $^{1}$. Gerd Huber ${ }^{2}$}

Lukas Weiser

Lukas.Weiser@med.uni-goettingen.de

1 Department of Trauma Surgery, Orthopaedic Surgery and Plastic Surgery, University Medical Center Göttingen, Robert-Koch-Str. 40, 37099 Göttingen, Germany
2 Institute of Biomechanics, TUHH Hamburg University of Technology, Hamburg, Germany

3 Institute of Forensic Medicine, University Medical Center Hamburg-Eppendorf, Hamburg, Germany 